\title{
Japan's successful launch of first marine observation satellite
}

Tokyo

JAPAN's first marine observation satellite, MOS-1, was successfully launched from the National Space Development Agency's (NASDA) space centre in Tanegashima island off Kyushu on 19 February. The launch marks the end of an era of total dependence on US rocket technology and gives another boost to the morale of Japan's space engineers.

The satellite, named Momo (peach blossom), lifted off at 10.23 a.m. local time aboard a two-stage N-II rocket. After passing over Australia and Antarctica, the $740-\mathrm{kg}$ satellite separated from the second stage over South America and entered a Sun-synchronous polar orbit at an altitude of just over $900 \mathrm{~km}$ about an hour after launch. Signals from the satellite were picked up immediately after separation at Kourou station of the European Space Agency in French Guiana.

Momo is equipped with three scanners: a multi-spectral electronic self-scanning radiometer with $50-\mathrm{m}$ resolution in the visible and near-infrared to monitor water turbidity, red tides, waves and ice distribution over the sea, and vegetation, geology, water resources and snow cover over land; a visible and thermal infrared radiometer to scan snow, cloud, ice and water temperature distribution; and a microwave radiometer that will make cloud wa-

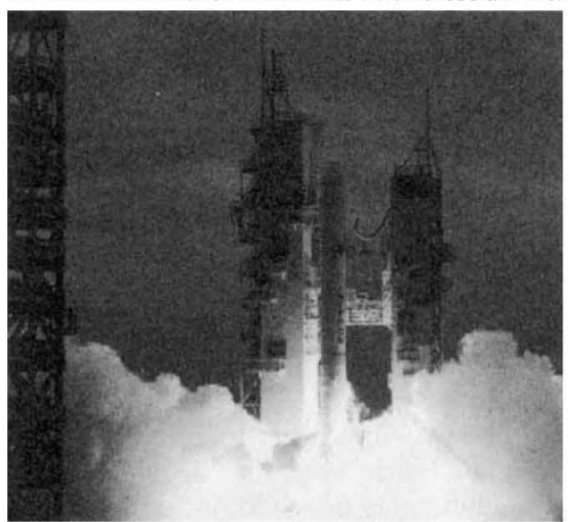

ter content, rainfall and snowfall measurements. The scanners lack the resolution of France's SPOT-1 satellite, which can pick up objects $10 \mathrm{~m}$ across when in panachromatic mode. Momo is the world's only marine observation satellite following the demise of the US's Seasat-1 shortly after launch in 1978. And its Sun-synchronous polar orbit allows coverage of almost the entire surface of the globe, bringing the satellite back to the same spot every 17 days. In addition to NASDA's Earth Observation Center north of Tokyo, ground stations in Spain, Norway, Thailand and the Antarctic will receive data directly from the satellite.

The N-II rocket that carried the satellite aloft is based entirely on US rocket technology including the inertial guidance system which is a 'black box' taken from the US Delta rocket. But this is the last N-II launch and in future NASDA will use rockets largely or entirely developed in Japan. The H-I rocket, which was successfully launched last summer, has only US components in the first stage; the H-II, due to be completed in 1992, will be entirely made in Japan.

NASDA executive vice-president $\mathrm{S}$. Sonoyama is noncommittal on whether Japan will enter the commercial space race with the $\mathrm{H}$-II. But other officials know they must reduce launch costs for geostationary satellites from the present level of Y30 million $(\$ 200,000)$ per $\mathrm{kg}$ for the $\mathrm{H}$-I to $\mathrm{Y} 8$ million per kg to be commercially viable.

The H-II will have a payload capacity of only $2,000 \mathrm{~kg}$ for geostationary satellites, half the capacity of Ariane-5. But Sonoyama believes conventional geostationary satellites will not rise above 2,000 $\mathrm{kg}$ because of difficulties of launching heavy satellites; instead he sees the future in multipurpose space platforms.

The Ministry of International Trade and Industry, the Institute of Space and Astronautical Sciences affiliated with the Ministry of Education, Science and Culture, and NASDA are jointly developing an experimental space platform that will be launched by 1993 at the earliest by an $\mathrm{H}$-II rocket and brought back by the US space shuttle. Although current specifications for the H-II limit it to satellites up to $3.7 \mathrm{~m}$ in diameter, plans are being made to increase this to $4.6 \mathrm{~m}$ for space shuttle compatibility. And the H-II could launch large payloads (up to $4,000 \mathrm{~kg}$ ) by augmenting the second-stage engine and adding boosters. Thus the next generation of satellites does seem within Japan's future launch capabilities.

The only remaining barrier to Japan's entry to the commercial market is the fishermen of Tanegashima, who restrict NASDA to two 45-day launch seasons in summer and winter, claiming that falling rocket boosters damage their fishing grounds. But even this may not be a problem. Masashi Motchizuki, director of the $\mathrm{H}$-II launch vehicle group, confidently predicts that 10 launches could be made during the summer season alone.

Since Japan launched its first satellite in 1970 , there has been only one failure out of 35 satellites, an experimental communications satellite launched in 1979. In this age of space disasters and soaring insurance costs for satellites, reliability will probably be Japan's strongest selling point.

\section{Safety fears in nuclear debate}

\section{London}

THE safety risks of nuclear energy have still not been properly assessed and there is no proper emergency procedure to cope adequately with another Chernobyl. These fears surfaced in public debate last week as British parliamentarians from all political parties expressed the growing disquiet among some members of the public about the safety of nuclear power.

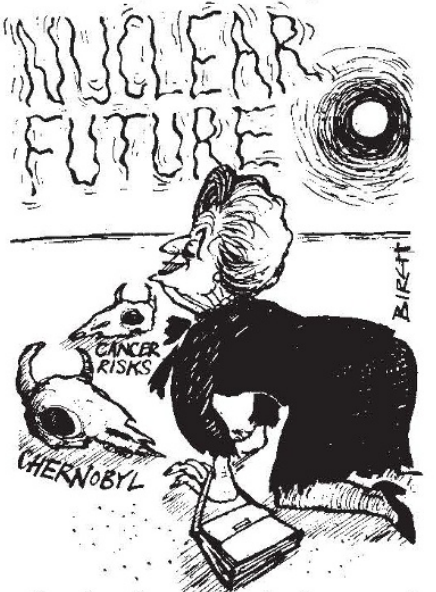

At the beginning of the week, the House of Commons debated the findings of the 109-chapter report, prepared by Sir Frank Layfield, on the proposed pressurized-water reactor (PWR) to be built by the Central Electricity Generating Board (CEGB) on the Suffolk coast. Despite the opposition, there is little doubt that the government will approve the reactor, estimated to cost about $£ 1,300$ million.

The leader of the Liberal Party, $\mathrm{Mr}$ David Steel, was typical of those who consider the conclusions of the Layfield report on safety to be inadequate. In a letter to $\mathrm{Mr}$ Peter Walker, the Energy Secretary, Steel demanded that the risks of civil nuclear power be assessed and made public: "It [the report] appears to suggest that Sizewell B will be acceptably safe only if the economic benefits are large enough to justify the scale of the risk involved. Or, put even more directly, that there are safety risks involved but that these will be acceptable if the economic benefits are big enough."

The public debate on Sizewell B resurrected the fears about Chernobyl. Although the National Radiological Protection Board (NRPB) tried to inform all the local authorities seeking guidance in the immediate wake of the disaster, the "arrangements" to cater for such an emergency proved inadequate.

As a consequence, NRPB has advised the Department of the Environment, which is drawing up the new procedures, to create a national emergency telecommunications network. Bill Johnstone 